\title{
Synthesis and characterization of biobased epoxy monomers derived from D-glucose
}

\author{
Zsolt Rapi ${ }^{1}$, Beáta Szolnoki ${ }^{1}$, Péter Bakó ${ }^{1}$, Péter Niedermann ${ }^{2}$, Andrea Toldy $^{2}$, Brigitta \\ Bodzay $^{1}$, György Keglevich ${ }^{1}$, György Marosi ${ }^{1{ }^{*}}$ \\ ${ }^{1}$ Department of Organic Chemistry and Technology, Faculty of Chemical Technology and \\ Biotechnology, Budapest University of Technology and Economics, Budafoki út 8, 1111 \\ Budapest, Hungary \\ ${ }^{2}$ Department of Polymer Engineering, Faculty of Mechanical Engineering, Budapest \\ University of Technology and Economics, Müegyetem rkp. 3, 1111 Budapest, Hungary \\ *Corresponding author.e-mail: gmarosi@mail.bme.hu, tel: +36 14633654
}

\begin{abstract}
This paper reports the preparation of newly synthesized sugar-based epoxy monomers, suitable for replacing petrochemical-derived epoxy resins of high thermal stability. Several bitri- and tetrafunctional epoxy components were prepared from D-glucose, among them the glucopyranoside- and glucofuranoside-based trifunctional ones proved to be the most promising for high-tech applications. The applicability of the synthesized compounds as epoxy monomers was investigated by curing probes with a model aromatic amine-type hardener. The curing enthalpy of the bioepoxy resins were examined, and compared to theoretical values, as well as the glass transition temperature, which is a crucial parameter when determining the potential fields of application of the bioresins. $\mathrm{T}_{\mathrm{g}}$ values up to $175^{\circ} \mathrm{C}$ were reached, while the thermal degradation of the cured resins start at around $300{ }^{\circ} \mathrm{C}$.
\end{abstract}

Keywords: renewable epoxy resin, synthesis, D-glucose, glass transition temperature, thermal stability

\section{Introduction}

In recent decades polymers derived from renewable resources became increasingly important as sustainable, eco-efficient and biodegradable products. The aim is to replace, at least partially, certain petroleum-based monomers ${ }^{1-7}$, such as diglycidyl ether of bisphenol A (DGEBA), which is used extensively as epoxy component of thermosetting polymers. The review of Auvergne et al. summarizes the recent works on the synthesis of bio-based epoxide 
materials for this purpose ${ }^{8}$. Besides the fossil origin, the recognized estrogenic properties of bisphenol A (BPA) also intensify the research activities in this field ${ }^{9}$. The chemical bonds that link bisphenol A into the polymer backbone are not completely stable; thus, the polymer may release, with time, a small amount of BPA, which is toxic to living organisms ${ }^{9}$.

Synthesis methods for biobased polymers have been developed starting from different natural materials, such as vegetable oil ${ }^{10-13}$, fatty $\operatorname{acids}^{14}, \operatorname{rosin}^{15,16}$, wood biomass ${ }^{17}$, industrial $\operatorname{lignin}^{17,18}$ and $\operatorname{starch}^{19}$. From a life-cycle perspective, sugar is a renewable resource that has the potential to be used as an alternative to petroleum-based polymers. At the same time, the development of new high value products and new concepts in sugar manufacturing could be an answer ${ }^{20}$ to the challenge of both oversupply and low prices in that field ${ }^{21}$.

The presence of highly reactive hydroxyl group in the very common and readily available carbohydrates enables the synthesis of a wide variety of monomers suitable for making different classes of polymers ${ }^{22-26}$. The multifunctionality of these compounds necessitates specific group protection if linear polymers with high molecular weight are desired. Carbohydrate-based polycondensates can typically show increased hydrophilicity, lower toxicity and higher susceptibility to biodegradation, compared to those coming from petrochemical feedstock.

The review of Linhardt et al. gives an excellent update on the synthesis and application of carbohydrate-containing polymers till $2001^{27}$, summarizing the knowledge accumulated on the synthetic carbohydrate-based polymers, which are increasingly explored as biodegradable, biocompatible, and biorenewable materials applicable as water absorbents, chromatographic supports, and medical devices. Later on, L-arabinitol- and xylitol-based polymers ${ }^{28,29}$, and Dmannitol-, galactitol- and galactaric acid-based polyesters ${ }^{30-32}$ have been prepared. Synthesis and characterization of polyuretane from a D-glucamine-based monomer ${ }^{33}$, as well as that of polyamides from galactaric, xylaric, D-glucaric and D-mannaric acids ${ }^{34-36}$ have been also reported.

Regarding epoxies, the use of natural polysaccharides was investigated in the synthesis of biobased epoxy monomers aiming to replace DGEBA. One group of the most promising sugar-derivatives as starting material are dianhydrohexitols, such as isosorbide, isomannide, isoidide, derived from D-glucose, D-mannose and L-fructose, respectively. The synthesized diglycidyl ether of isosorbide (1,4:3,6-dianhydro-D-sorbitol) was successfully incorporated into thermosets and thermoplastics in several cases. Some isosorbide-based thermosets had dry mechanical properties comparable to $\mathrm{DGEBA}^{37-41}$, however, the glass transition temperatures of the amine-cured networks are still lower than expected ${ }^{40-42}$. 
The aim of the present work was to prepare high performance bio-based epoxy components derived from D-glucose, an inexpensive, easily available and renewable starting material, which has not yet been applied as epoxy monomer precursor, and to characterize their curing properties, glass transition temperature and thermal stability.

\section{Experimental}

The materials used in the organic syntheses, as well as the applied model curing agent, DDM (4,4'-diaminodiphenyl methane, amine hydrogen equivalent weight: $49.6 \mathrm{~g} / \mathrm{eq}$ ) were purchased from Sigma-Aldrich. As reference epoxy component DGEBA was applied (ER 1010, epoxy equivalent weight: $180 \mathrm{~g} / \mathrm{eq}$; viscosity: 12 Pa.s), received from Ipox Chemicals. The viscosity of the synthesized liquid epoxy monomers was determined in steady state flow rotating mode at room temperature, using a TA Instruments AR2000 rheometer. The shear rate was between 4 and $40 \mathrm{~s}^{-1}$, the sample was placed between a rotating 40-mm-diameter plane disc and a controlled-temperature plane sheet. 5 points have been recorded in each decade of shear rate, 3 minutes have been left at each point to reach equilibrium, 3 consecutive measurements had to be in a $5 \%$ difference range before continuing to the next shear rate point.The curing process was monitored with TA instruments DSC Q2000 type DSC equipment in $50 \mathrm{ml} / \mathrm{min}$ nitrogen flow. Tzero type aluminium pans were used, the sample size was between 5-10 mg. The applied three-step temperature program consisted of heat/cool/heat cycles: after a linear ramp from $25-250{ }^{\circ} \mathrm{C}$ with $5{ }^{\circ} \mathrm{C} / \mathrm{min}$ heat rate, the sample was cooled down to $0{ }^{\circ} \mathrm{C}$ with $50{ }^{\circ} \mathrm{C} / \mathrm{min}$ cooling rate, followed by a second linear heating ramp from $0-250{ }^{\circ} \mathrm{C}$ with $5{ }^{\circ} \mathrm{C} / \mathrm{min}$ heating rate. From the first ramp the curing enthalpy was determined, while from the second one the glass transition temperature of the different systems was received.

The completion of the curing was also monitored by Raman spectrometry, using a Horiba Jobin-Yvon LabRAM system coupled with an external $785 \mathrm{~nm}$ diode laser source and an Olympus BX-40 optical microscope. The spectrograph was set to provide a spectral range of 200-2000 $\mathrm{cm}^{-1}$ and $3 \mathrm{~cm}^{-1}$ resolution. Objectives of $10 \times$ for the starting materials and $50 \times$ magnification for the cured sample were used for spectrum acquisition.

The thermal stability of the different compositions was determined by TGA measurements using Setaram Labsys TG DTA/DSC instrument in the temperature range of $25-800{ }^{\circ} \mathrm{C}$ at a heating rate of $10{ }^{\circ} \mathrm{C} / \mathrm{min}$ under nitrogen gas flow rate of $30 \mathrm{ml} / \mathrm{min}$. About $15-20 \mathrm{mg}$ of sample was used in each test. 
Shore D hardness of several cured epoxy networks was investigated using a Zwick Roell H04.3150 type hardness tester. At least ten points of each sample were tested, according to ISO 868.

Specimens for the Raman and hardness measurements of the synthesized trifunctional bioepoxy resins and the reference DGEBA were cured in silicon mould, with a temperature program of $2 \mathrm{~h}$ at $120^{\circ} \mathrm{C}$ and $2 \mathrm{~h}$ at $150{ }^{\circ} \mathrm{C}$.

\section{Results and discussion}

\subsection{Synthesis of D-glucose-based epoxy components}

In this part, the syntheses of $\alpha$-D-glucopyranoside- and glucofuranoside-based epoxy monomers derived from D-glucose are presented. Glucose is an easily available commercial product and it is a "green", inexpensive and non-toxic starting material in organic syntheses.

Our aim was to prepare D-glucose-derivatives with two or more epoxy groups making them suitable for polymerization. The exact recipes of the synthetic procedures can be found in the Supplementary data.

Methyl- $\alpha$-D-glucopyranoside (that is a commercial product) can be obtained by the condensation of D-glucose with methanol in the presence of cation-exchange resin as catalyst

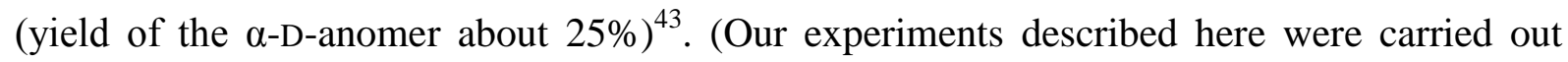
starting from methyl- $\alpha$-D-glucopyranoside, but, a mixture of $\alpha$ - and $\beta$-anomers is also perfectly suitable for the purpose of the polymers). Methyl 4,6- $O$-benzylidene- $\alpha-\mathrm{D}-$ glucopyranoside (1) was prepared in the condensation of methyl- $\alpha$-D-glucoside with benzaldehyde using zinc chloride as the catalyst (Scheme 1). After a reaction of $4 \mathrm{~h}$ at room temperature, the intermediate 1 was obtained in a yield of nearly $72 \%$ by crystallization ${ }^{44}$. Treatment of compound $\mathbf{1}$ with an excess of allyl bromide and solid potassium hydroxide in refluxing toluene gave diallyl ether 2 , after crystallization in a yield of $90 \%$ (Scheme 1) ${ }^{45}$. Diallyl ether 2 was converted by treatment with hydrogen peroxide into diglycidyl ether derivative 3 in methanol in the presence of $\mathrm{K}_{2} \mathrm{CO}_{3}$ and benzonitrile by the method of Lindberg ${ }^{46}$. After chromatography the yield of the solid crystalline product $\mathbf{3}$ was $40 \%$ (Scheme 1) (see Supplementary data). 


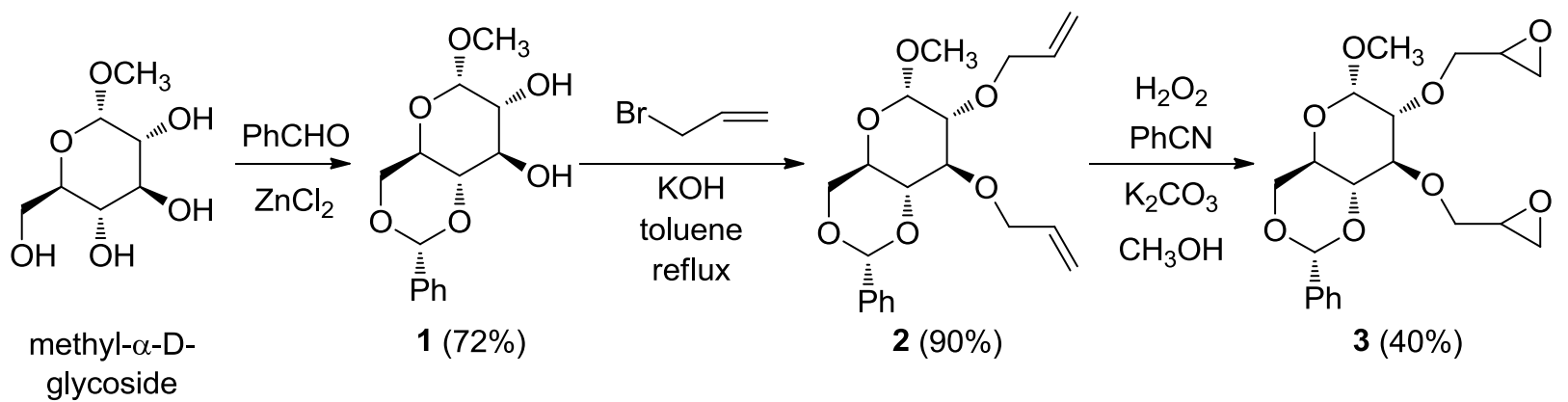

Scheme 1 Synthesis of bifunctional epoxy component derived from D-glucose

A one step synthesis of glucose-based diglycidyl ether $\mathbf{3}$ was also performed using different methods. The reaction of methyl-4,6- $O$-benzylidene- $\alpha$-D-glucopyranoside (1) with epichlorohydrin has not been described in the literature (Scheme 2). This reaction was carried out under different reaction conditions with different bases in various solvents. In the optimal case, a large excess of epichlorohydrin was applied as reagent and also as solvent, but the pure compound having two epoxypropyl groups (3) could not be prepared. Solvent free reactions of compound $\mathbf{1}$ in the presence of $\mathrm{Bu}_{4} \mathrm{NHSO}_{4}$ resulted in mixtures of mono- and disubstituted products. These mixtures contained 1.3 epoxypropyl groups per molecule in average, thus completely double substituted glucose derivative $\mathbf{3}$ could not be obtained by these methods. The failure of these attempts may be caused by the nature of the free hydroxyl groups. The secondary $\mathrm{OH}$ functions are less reactive than the primary ones, due to this, direct O-alkylation of the former ones requires strong base $($ e.g. $\mathrm{NaH})$ or highly activated alkylating agent (e.g. allyl bromide). Formation of glycidyl ether can involve not only nucleophile substitution, but a two-step mechanism (ring opening and intramolecular cyclization). The attack of one of the hydroxyl groups on the epoxide ring of the epichlorohydrin results in an intermediate containing a newly formed secondary $\mathrm{OH}$ function. The reactivity of the new alcohol group is comparable to that of the other free one attached to the carbohydrate ring due to their similar $\mathrm{pK}_{\mathrm{a}}$ values, which leads to their competition in the ring-opening reaction. In addition, the steric hindrance of the hydroxyl function bound to the six-membered ring is increased by the group formed on the other, already substituted $\mathrm{OH}$ function.
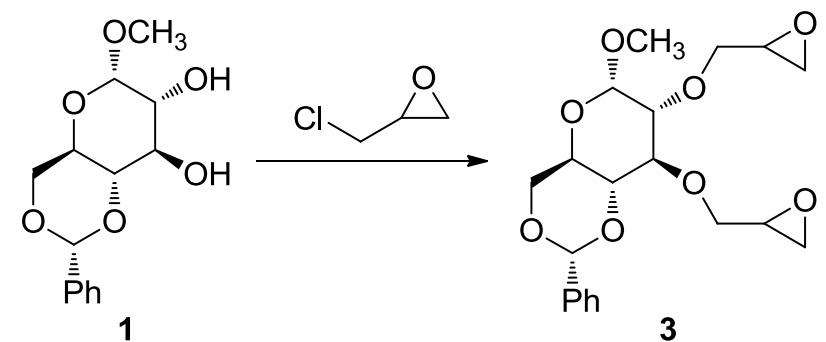

Scheme 2 One-step reaction with epichlorohydrin 
The synthesis of compound 7 having three glycidyl ether groups was carried out using two methods (Scheme 3). Preparation of allyl- $\alpha-D-$ glucopyranoside (4) was performed by the reaction of D-glucose and allyl alcohol in the presence of boron trifluoride diethyl etherate $\left(\mathrm{BF}_{3} \mathrm{Et}_{2} \mathrm{O}\right)$ as the catalyst in $26 \%$ yield $(5 \mathrm{~h} \text {, reflux, column chromatography })^{47}$. Selective protection of the 4- and 6-hydroxyl groups of the allyl- $\alpha$-D-glucopyranoside with benzaldehyde dimethylacetal using $p \mathrm{TsOH}$ as catalyst was accomplished in DMF resulting in compound 5 in good yield $(76 \%)^{48}$ (see Supplementary data).

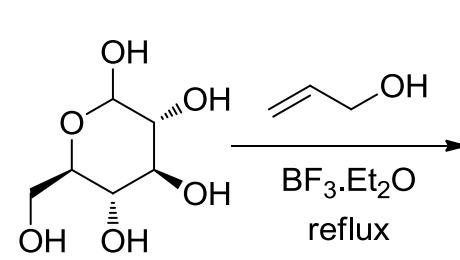

D-glucose<smiles>C=CCO[C@H]1O[C@H](CO)[C@@H](O)[C@H](O)[C@H]1O</smiles>

$4(26 \%)$

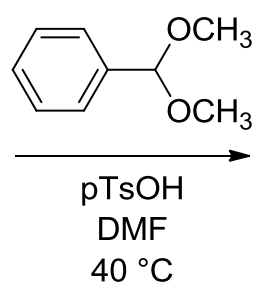<smiles>C=CCO[C@H]1O[C@@H]2CO[C@H](c3ccccc3)O[C@H]2[C@H](O)[C@@H]1O</smiles>

$5(76 \%)$

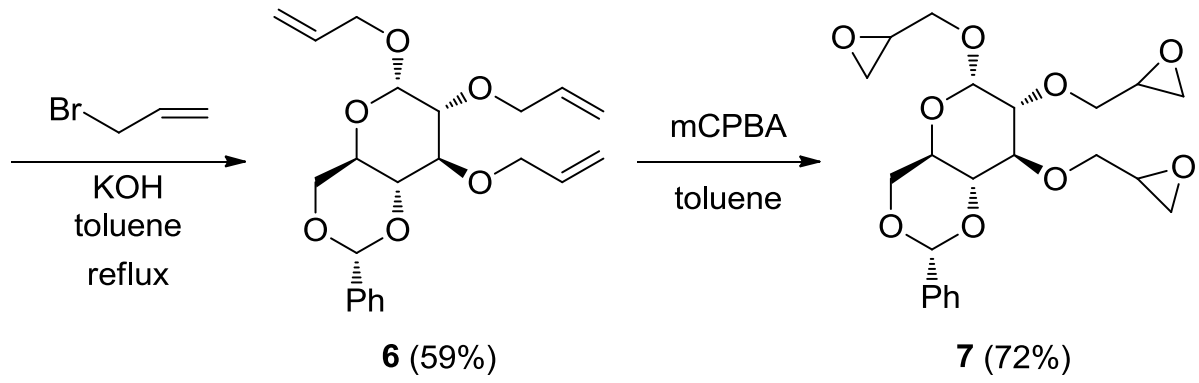

Scheme 3 Synthesis of glucopyranoside-based trifunctional epoxy component

The one pot method for preparation of compound 5 proved to be simpler ${ }^{48}$. D-glucose was refluxed in allyl alcohol in the presence of $\mathrm{CF}_{3} \mathrm{SO}_{3} \mathrm{H}$ for $48 \mathrm{~h}$. After the removal of the alcohol and the acid, the residue was reacted in DMF with benzaldehyde dimethylacetal using $p$ TsOH as catalyst $\left(40^{\circ} \mathrm{C}, 5 \mathrm{~h}\right)$. After the working up procedure the crude product was a mixture of the $\alpha$ - and $\beta$-anomers. Allyl-4,6- $O$-benzylidene- $\alpha$-d-glucopyranoside (5) was obtained in pure form after crystallization from ethanol in a yield of $23 \%{ }^{48}$. If the pure $\alpha$ epimer was not separated, the mixture of $\alpha$ and $\beta$ isomers could be obtained with the yield of $45 \%$. The reaction of compound 5 with allyl bromide in toluene in the presence of potassium hydroxide gave the corresponding 1,2,3-tri- $O$-allyl derivative 6 (Scheme 3$)^{49}$. Epoxidation of 6 with $m$-chloroperbenzoic acid in toluene resulted in (2',3'-epoxypropyl)-2,3-di-O-(2',3'epoxypropyl)-4,6- $O$-benzylidene- $\alpha$-D-glucopyranoside (7) after chromatography with $72 \%$ yield of the crystalline product (Scheme 3) (see Supplementary data). 
The preparation of the tetraallyl-derivative (8) was carried out by the reaction of methyl- $\alpha-\mathrm{D}-$ glucoside and allyl bromide in 1,4-dioxane in the presence of potassium hydroxide. After chromatography the yield of product 8 was $40 \%$. The tetraepoxy-glucopyranoside-derivative (9) was obtained by the oxidation of compound $\mathbf{8}$ with $\mathrm{m}$-chloroperbenzoic acid in toluene, as described above. The yield of the crystalline product 9 was $50 \%(\text { Scheme } 4)^{50}$.

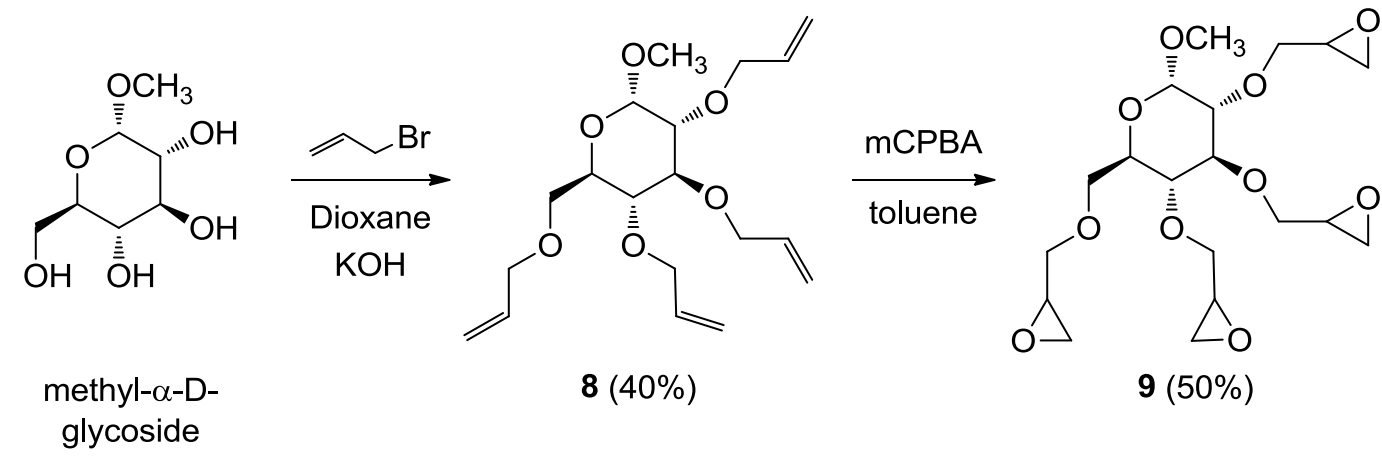

Scheme 4 Synthesis of glucopyranoside-based tetrafunctional epoxy component

D-Glucose was also the starting material of the isopropylidene- $\alpha$-D-glucofuranoside-based epoxy component. The key compound was the 1,2-di- $O$-isopropylidene- $\alpha$-D-glucofuranoside (11) which could be obtained by two methods (Scheme 5). The reaction of D-glucose with acetone (reagent and solvent) in the presence of iodine (as the catalyst) resulted in 1,2:5,6-di$O$-isopropylidene- $\alpha$-D-glucofuranoside (10) in good yield (59\%) after purification by crystallization $^{51}$. Selective removal of the 5,6-O-isopropylidene group of the intermediate was performed with diluted sulfuric acid in methanol $(24 \mathrm{~h}$, room temperature, yield after crystallization is 65\%) (Scheme 5) ${ }^{51}$. 
<smiles>C[C@H]1[C@@H](CO)OC(O)[C@H](O)[C@H]1O</smiles>

D-glucose<smiles>CC1(C)OC[C@H](C2O[C@@H]3OC(C)(C)O[C@@H]3C2O)O1</smiles>

$10(59 \%)$<smiles>O[AsH3](O)(O)O</smiles><smiles>CC1(C)OC2OC(C(O)CO)C(O)C2O1</smiles>

$11(65 \%)$

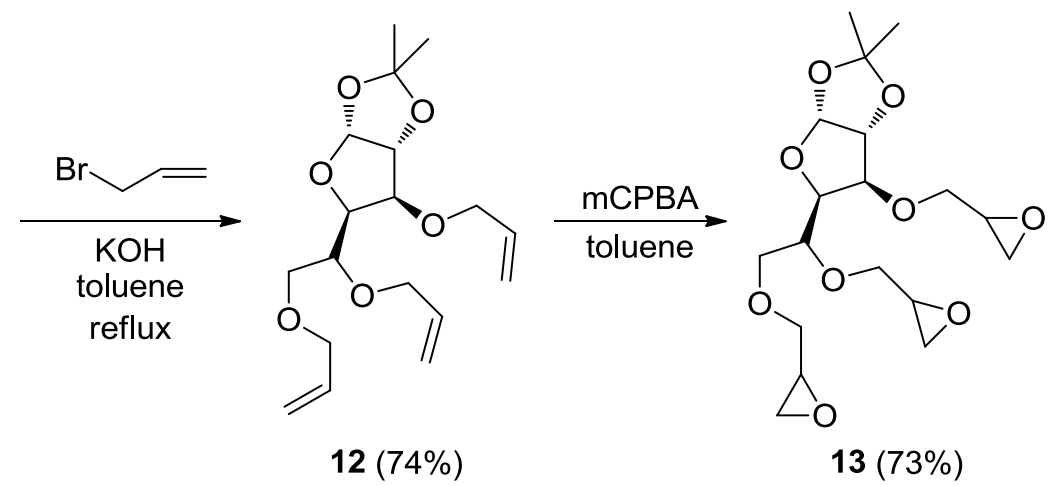

Scheme 5 Synthesis of glucofuranoside-based trifunctional epoxy component

However, the one pot method for preparation of compound $\mathbf{1 1}$ proved to be more effective $\mathrm{e}^{52}$. First, D-glucose was treated with acetone in the presence of sulfuric acid, then after neutralization and evaporation of the reaction mixture, the crude product $(1,2: 5,6-\mathrm{di}-O$ isopropylidene- $\alpha$-D-glucofuranoside) was treated with hydrochloric acid giving intermediate $\mathbf{1 1}$ in a yield of $43 \%$ after recrystallization (Scheme 5). The reaction of compound 11 with mixture of potassium hydroxide and allyl bromide in toluene gave the corresponding 3,5,6-tri$O$-allyl derivative 12 in yield of $74 \%$ applying a modification of the method by Bullock ${ }^{53}$ (Scheme 5). Epoxidation of allyl ether 12 with $m$-chloroperbenzoic acid in toluene resulted in 3,5,6-tri- $O$-(2',3'-epoxypropyl)-1,2- $O$-isopropylidene- $\alpha$-D-glucofuranoside (13) in a yield of $76 \%$ after purification by chromatography (Scheme 5) ${ }^{50}$ (see Supplementary data). The product is yellow oil, with a viscosity of $3.77 \mathrm{~Pa} . \mathrm{s}$ at room temperature.

\subsection{Curing properties of the synthesized components}

For investigating the applicability of the synthesized glucose-based epoxy monomers DSC measurements were carried out. For the curing probes, 4,4'-diaminodiphenyl methane (DDM) model compound was applied as hardener. The synthesized components were prepared in $>95 \%$ purity, their epoxy equivalents could be determined from their molecular weight (Table 1). The epoxy equivalent values were also determined by titration, and the results were 
in good accordance with the theoretical values. The appropriate mixing ratio of the epoxy and amine components was calculated from the epoxy equivalents and the amine number of the model hardener DDM, in order to reach maximal crosslink-density. For the measurements, the powdered or liquid epoxy monomers were mixed with appropriate amount of the powdered hardener in a mortar in order to reach homogenous dispersion of the components.

The curing enthalpies of the different bioepoxy resins were determined from the first heating ramp (Table 1). As it can be seen, the onset point of the curing is about $120{ }^{\circ} \mathrm{C}$ in most cases. The peak temperature is also in the same temperature range for compounds 3 (GP2E, glucopyranoside-based diepoxy), 7 (GP3E, glucopyranoside-based triepoxy) and 13 (GF3E, glucofuranoside-based triepoxy), however compound 9 (GP4E, glucopyranoside-based tetraepoxy) shows somewhat lower values. As the reaction enthalpy of an epoxy - amine system (from -118 to $-100 \mathrm{~kJ} / \mathrm{mol}$ of epoxy groups ${ }^{54}$ or from -111 to $-98 \mathrm{~kJ} / \mathrm{mol}^{55}$ ) is independent from the molecular structure of the components, ${ }^{54,55}$ the degree of cure can be determined (Table 1 rows 6-8). For the calculations, -105 kJ/mol of epoxy groups was chosen as an average value. From the curing enthalpy measured in DSC (J/g), the enthalpy in $\mathrm{kJ} / \mathrm{mol}$ of epoxy groups was calculated, applying the mixing ratio of the two components (Table 1, row 7). These calculated values were compared to the theoretical value $(105 \mathrm{~kJ} / \mathrm{mol} \mathrm{pf}$ epoxy groups) to determine the degree of cure (Table 1, row 8). In the case of the oily GF3E bioepoxy monomer, the calculated enthalpy is in good accordance with the theoretical value, as well as in the case of the reference DGEBA - DDM system. From the results it can be seen, that the reaction between the glucopyranoside-based epoxy components and the hardener was not complete, the degree of cure is only $60-80 \%$. This phenomenon can be explained by the solid state of these bioepoxies: during the mixing in the mortar, no molecular level homogenization of the two components was reached, thus, no full curing could be achieved. (Neither the solutions of the components, nor the mixtures of the melted molecules are suitable for determining the curing by DSC method. The presence of the solvent, or the already started reaction between the components would falsify the results.) 
Table 1 Curing behaviour of the synthesized bioepoxy components

\begin{tabular}{|l|l|l|l|l|l|}
\hline $\begin{array}{l}\text { epoxy } \\
\text { component }\end{array}$ & GP2E & GP3E & GP4E & GF3E & DGEBA \\
\hline $\begin{array}{l}\text { epoxy equivalent } \\
\text { weight (g/eq) }\end{array}$ & 197 & 145 & 104 & 129 & 180 \\
\hline $\begin{array}{l}\text { quantity of DDM } \\
\text { used for 100 g of } \\
\text { epoxy monomer }(\mathrm{g})\end{array}$ & 25.2 & 34.2 & 47.7 & 38.5 & 27.6 \\
\hline $\begin{array}{l}\text { onset point of curing } \\
\left({ }^{\circ} \mathrm{C}\right)\end{array}$ & 127.4 & 98.0 & 117.6 & 127.6 & 121.4 \\
\hline peak of curing $\left({ }^{\circ} \mathrm{C}\right)$ & 164.3 & 127.3 & 143.0 & 158.4 & 148.8 \\
\hline $\begin{array}{l}\text { measured enthalpy } \\
\text { of curing (J/g) }\end{array}$ & 258.0 & 395.3 & 535.5 & 530.6 & 432.1 \\
\hline $\begin{array}{l}\text { calculated enthalpy } \\
\text { of curing (kJ/mol of } \\
\text { epoxy groups) }\end{array}$ & 63.69 & 77.18 & 82.74 & 95.11 & 99.21 \\
\hline degree of cure $(\%)$ & 60.7 & 73.5 & 78.8 & 90.6 & 94.5 \\
\hline $\begin{array}{l}\text { glass transition } \\
\text { temperature }\left({ }^{\circ} \mathrm{C}\right)\end{array}$ & 76 & 154 & 130 & 177 & 174 \\
\hline
\end{tabular}

The glass transition temperatures $\left(\mathrm{T}_{\mathrm{g}}\right)$ of the different glucose-based epoxy networks (Table 1) show variable values. As expected, the lowest $T_{g}$ was measured for the bifunctional glucopyranoside-based component (3, GP2E), due to the low functionality, and low degree of cure. When comparing the glucopyranoside-based tri- and tetrafunctional resins, in contrast to the expectations, not the higher functionality provided the higher $\mathrm{T}_{\mathrm{g}}$. This phenomenon can be explained by the higher flexibility of GP4E structure (compound 9), as the rigid bicyclic part is missing in this case, the segmental movements are less limited. Taking into account the lower degree of cure of the glucopyranoside-based bioepoxies, under technological circumstances when the presence of solvent or the melted state of the components is not disturbing, even higher $\mathrm{T}_{\mathrm{g}}$ values are foreseen. The highest $\mathrm{T}_{\mathrm{g}}$ value $\left(177^{\circ} \mathrm{C}\right)$ was reached using the glucofuranoside-based trifunctional epoxy component (13, GF3E), owing to the compact structure of the molecule, even higher than that for the reference DGEBA $\left(174{ }^{\circ} \mathrm{C}\right)$. 
The completion of the curing in the case of GF3E was also investigated by Raman spectrometry. The Raman spectra of the pure GF3E epoxy monomer, the model hardener (DDM) and the cured resin can be seen in Figure 1.

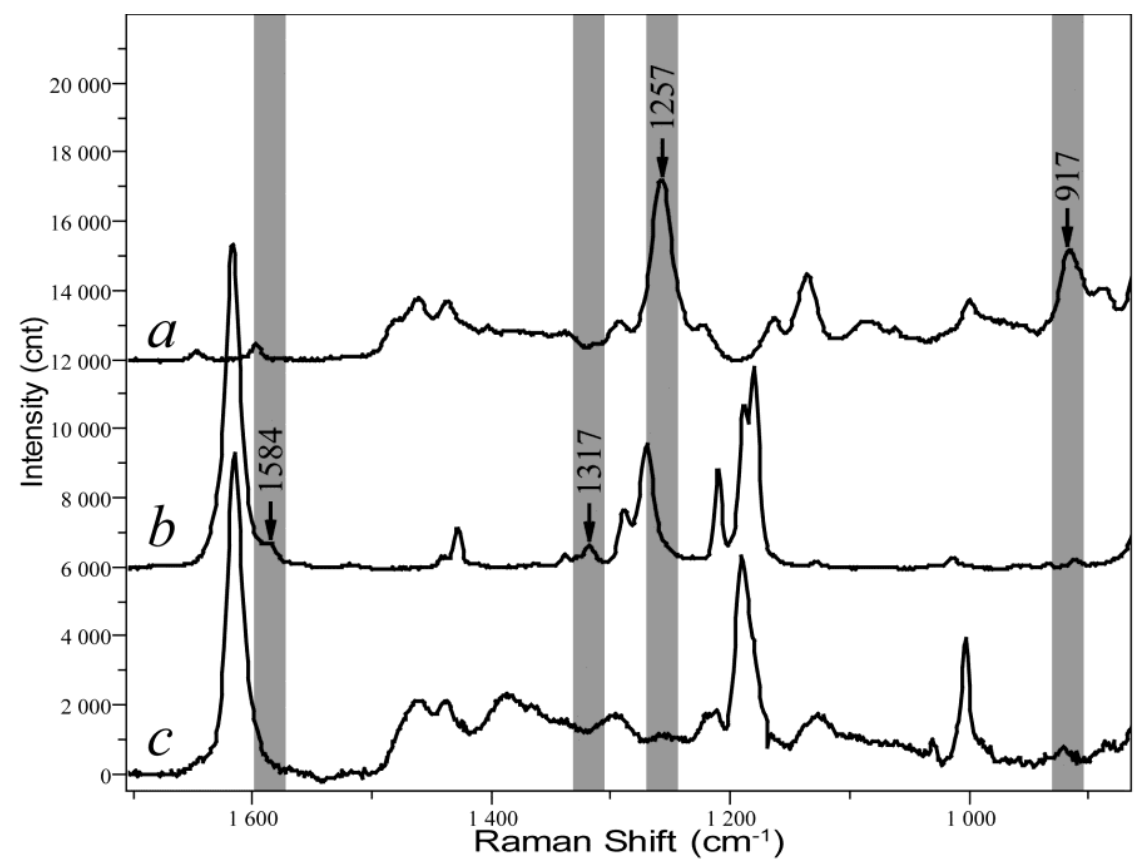

Figure 1 Raman spectra of GF3E epoxy component (a), DDM curing agent $(b)$ and the cured $\operatorname{resin}(c)$

The characteristic bands of the epoxy ring can be seen at 917 and at $1257 \mathrm{~cm}^{-1}$, respectively in the spectrum of GF3E (Figure $1 a$ ). At this region, the vibrations of the $\mathrm{NH}_{2}$ groups appear as weak peaks at 1317 and at $1584 \mathrm{~cm}^{-1}$ (Figure $1 \mathrm{~b}$ ). In the spectrum of the cured resin (Figure $1 \mathrm{c}$ ), the characteristic peaks of neither the epoxy component nor the amine-type hardener can be seen, which indicates complete reaction between the two components.

\subsection{Thermal stability of the synthesized bioepoxy resins}

The thermal stability of the cured bioepoxy networks was determined by TGA measurements (Figure 2 and Table 2). 


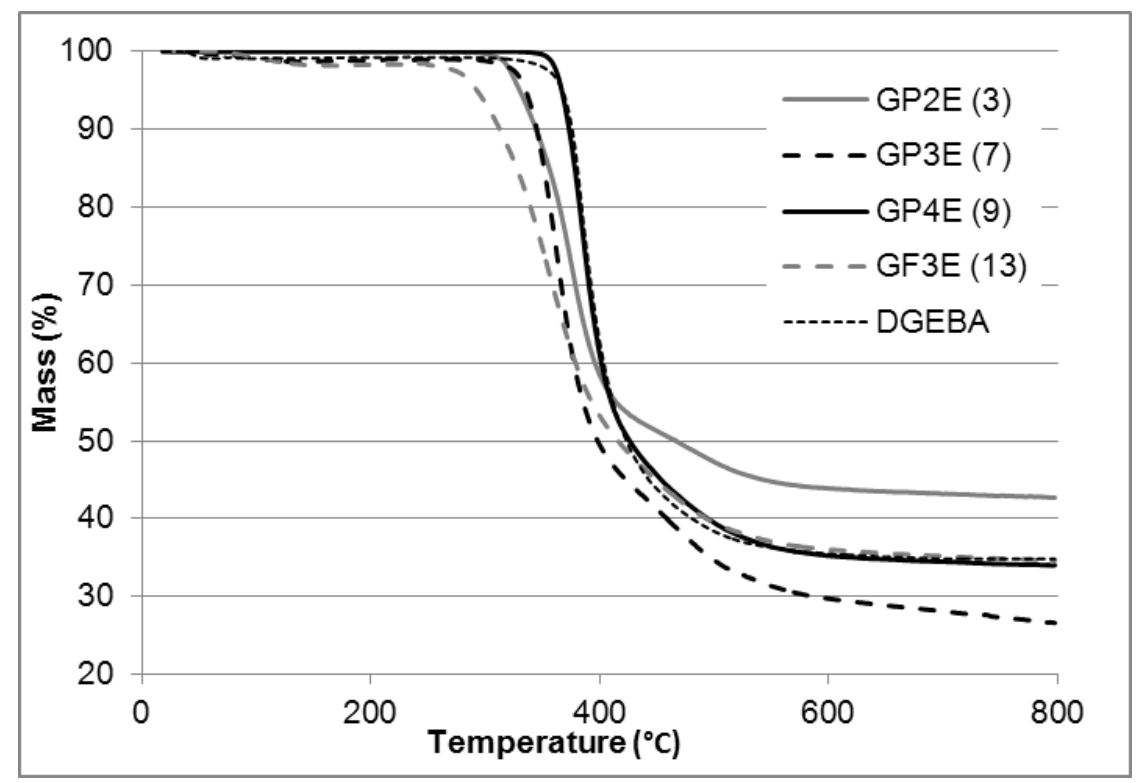

Figure 2 TGA curves of the different bioepoxy components cured with DDM

The degradation of the trifunctional glucofuranoside-based resin (GF3E) starts at the lowest temperature among the investigated systems, as the 1,2-O-isopropylidene group of the molecule 13 can easily split off, releasing acetone. The further decomposition of this sample is relatively slow. The bi- and trifunctional glucopyranoside-based resins (GP2E and GP3E) start to degrade at about $330{ }^{\circ} \mathrm{C}$, with the leaving of 4,6-O-benzylidene protecting group. The tetrafunctional epoxy component and the reference DGEBA show the same behaviour. These molecules have no easily breakable protecting groups, so the highest thermal stability can be reached (up to $360{ }^{\circ} \mathrm{C}$ ), however, their degradation rate is also high. The relatively high char yields of the synthesized bioepoxy compositions is very promising in respect of flame retardation (Table 2).

Table 2 Thermal degradation of the different bioepoxy compositions

\begin{tabular}{|l|l|l|l|l|l|}
\hline component & $\begin{array}{l}\mathrm{T}_{-5 \%} \\
\left({ }^{\circ} \mathrm{C}\right)\end{array}$ & $\begin{array}{l}\mathrm{T}_{-50 \%} \\
\left({ }^{\circ} \mathrm{C}\right)\end{array}$ & $\begin{array}{l}\mathrm{dTG}_{\max } \\
(\% / \min )\end{array}$ & $\begin{array}{l}\mathrm{T}_{\mathrm{dTGmax}} \\
\left({ }^{\circ} \mathrm{C}\right)\end{array}$ & $\begin{array}{l}\text { char yield } \\
(\%)\end{array}$ \\
\hline GP2E & 330.4 & 466.7 & -7.65 & 374.7 & 42.7 \\
\hline GP3E & 335.6 & 398.3 & -11.48 & 362.9 & 26.6 \\
\hline GP4E & 367.0 & 426.4 & -12.37 & 385.2 & 34.0 \\
\hline GF3E & 293.1 & 416.1 & -5.41 & 358.7 & 34.6 \\
\hline DGEBA & 367.7 & 423.6 & -13.43 & 384.1 & 34.8 \\
\hline
\end{tabular}

$\mathrm{T}_{-5 \%}$ : temperature at 5 mass $\%$ loss; $\mathrm{T}_{-50 \%}$ : temperature at 50 mass $\%$ loss, $\mathrm{dTG}_{\max }$ : maximum mass loss rate; $\mathrm{T}_{\mathrm{dTGmax}}$ : temperature belonging to $\mathrm{dTG}_{\max }$ 


\subsection{Hardness measurements}

As the synthesized trifunctional bioepoxy monomers (GP3E and GF3E) showed the highest $\mathrm{T}_{\mathrm{g}}$ values, their Shore D hardness was also determined and compared to that of the DGEBA. The results of the tests are summarized in Table 3.

Table 3 Shore D hardness of the resins

\begin{tabular}{|l|l|l|l|}
\hline $\begin{array}{l}\text { epoxy } \\
\text { component }\end{array}$ & GP3E & GF3E & DGEBA \\
\hline $\begin{array}{l}\text { Shore D } \\
\text { hardness }\end{array}$ & $74 \pm 4$ & $78 \pm 3$ & $75 \pm 3$ \\
\hline
\end{tabular}

The measured values for the bioepoxy networks are in good accordance with the value measured for the DGEBA-based one. Further mechanical measurements are planned in order to determine the applicability of the synthesized bioepoxies as matrix materials for high tech composites, however, the hardness values similar to DGEBA's, are very promising..

\section{Conclusions}

The aim of this study was to synthesize epoxy monomers from an inexpensive, renewable and easily available starting material, D-glucose. By protecting the hydroxyl groups in the 4 and 6 positions, bi- and trifunctional glucopyranoside-based epoxy components were synthesized via allylation of the free $\mathrm{OH}$-groups, followed by the epoxidation of the carbon-carbon double bond with $m$-chloroperbenzoic acid, having a relatively rigid, bicyclic backbone. By removing the 4,6-O-benzylidene protecting group, a tetrafunctional epoxy component was synthesized. Besides the glucopyranoside-based components, a glucofuranoside-based trifunctional molecule was also prepared: glucose was reacted with acetone, followed by the selective removing of the 5,6-O-isopropylidene group. The forming free hydroxyl groups were reacted first with allyl bromide, and then the allyl functions were epoxidized. Among the prepared components, the glucopyranoside-based tri- and tetrafunctional molecules have not yet been synthesized, while the other two compounds have not yet been cured to form epoxy resins.

Curing investigations were carried out from the prepared bioepoxy monomers; the diepoxide (compound 3), two triepoxides (7 and 13) and also the glucose-based tetraepoxy component (9) were cured successfully with a model hardener (DDM). The glass transition temperatures were also determined. The highest value was reached with the glucofuranoside-based trifunctional component, as the easy accessibility of the epoxy groups is combined with a 
relatively rigid bicyclic backbone. The thermal stability of the cured resins was investigated by TGA measurements. The degradation of the samples starts between 293 and $367^{\circ} \mathrm{C}$, while all the synthesized resins have relatively high char yields at $800{ }^{\circ} \mathrm{C}$ promising easy flame retardancy. The Shore D hardness, determined for the trifunctional bioepoxy networks, showed similar values to that measured for the reference DGEBA.

Based on the results, these innovative, renewable and easily synthesizable components, showing good performance as cured epoxy networks, are promising candidates for further investigations as bio-based high tech epoxy resins.

\section{Acknowledgements}

The research leading to these results has received funding from the European Union's Seventh Framework Programme (FP7/2007-2013) for the Clean Sky Joint Technology Initiative under grant agreement No. 298090. This work was financially supported by the New Széchenyi Development Plan (TÁMOP-4.2.1/B-09/1/KMR-2010-0002) and by the NFÜ EU_BONUS_12-1-2012-0026. The work reported in this paper has been developed in the framework of the project "Talent care and cultivation in the scientific workshops of BME" project. This research was realized in the frames of TÁMOP 4.2.4. A/1-11-1-2012-0001 „National Excellence Program - Elaborating and operating an inland student and researcher personal support system”. The project was subsidized by the European Union and co-financed by the European Social Fund. Andrea Toldy acknowledges the financial support received through János Bolyai Scholarship of the Hungarian Academy of Science.

\section{References}

1. T. E. Graedel, J. A. Howard-Grenville, Greening the industrial facility, perspectives, approaches and tools. Springer, New York, 2005.

2. D. L. Kaplan, Biopolymers from renewable resources. Springer Verlag, Berlin, 1998

3. A Gandini, In: J-P. Pascault, R. J. J Williams, eds. Epoxy polymers: new materials and innovations. Wiley-VCH, 2010

4. R. Wool, X. S. Sun, Biobased Polymers and Composites, Academic Press, New York, 2005

5. C. K. S. Pillai, Design. Monom. Polym., 2010, 13, 87-121

6. A. Gandini, Green Chem. 2011, 13, 1061-1083

7. M. N. Belgacem, A. Gandini, eds. Monomers, Polymers and Composites from Renewable Resources, Elsevier, Oxford, 2008

8. R. Auvergne, S. Calliol, G. David, B. Boutevin, J-P. Pascault, Chem. Rev., 2014, 114, 1082-1115

9. R. Chapin, Birth Defects Res, Part B, 2008, 3, 157-395

10. J. Lu, S. Khot, R. P. Wool, Polymer, 2005, 46, 71-80 
11. S-J. Park, F-L. Jin, J-R. Lee, Macromol. Rapid Comm., 2004, 25, 724-727

12. R. Wang, T. P. Schuman, Express Polym. Lett., 2013, 7, 272-292

13. H. Kalita, S. Selvakumar, A. Jayasooriyamu, S. Fernando, S. Samanta, J. Bahr, S. Alam, M. Sibi, J. Vold, C. Ulven, B. J. Chrisholm, Green Chem., 2014, 16, 19741986

14. X. Pan, P. Sengupta, D. C. Webster, Biomacromolecules, 2011, 12, 2416-2428

15. X. Q. Liu, W. Huang, Y. H. Jiang, J. Zhu, C. Z. Zhang, Express Polym. Lett., 2012, 6, 293-298

16. C. Mantzaridis, A-L. Brocas, A. Llevot, G. Cendejas, R. Auvergne, S. Caillol, S. Carlotti, H. Cramail, Green Chem., 2013, 15, 3091-3098

17. T. Koike, Polym. Eng. Sci., 2012, 52, 701-717

18. M. Fache, E. Darroman, V. Besse, R. Auvergne, S. Caillol, B. Boutevin, Green Chem., 2014, 16, 1987-1998

19. (a) A. M. L. Huijbrechts, J. Huang, H. A. Schols, B. Van Langen, , G. M. Visser, C. G. Boeriu, J. Polym. Sci. Part A: Polym. Chem. 2007, 45, 2734-2744

(b) A. M. L. Huijbrechts, R. Ter Haar, H. A. Schols, M. C. R. Franssen, C. G. Boeriu, E. J. R. Sudhölter, Carbohydr. Polym., 2010, 79, 858-866

20. M. A. Godshall, Int. Sugar J., 2001, 103, 378-384

21. B. L. Legendre, D. M. Burner, Biomass Bioenergy, 1995, 8, 55-61

22. H. R. J. Kricheldorf, Macromol. Sci. Rev. Macromol. Chem. Phys. 1997, C37, 599-631

23. O. Varela, H. A. Orgueira, Adv. Carbohydr. Chem. Biochem., 2000, 55, 137-174

24. M. Okada, Prog. Polym. Sci., 2001, 26, 67-104

25. A. J. Varma, J. F. Kennedy, P. Q. Galgali, Carbohydr. Polym., 2004, 56, 429-445

26. J. A. Galbis, M. G. García-Martín, Top Curr. Chem. 2010, 295, 147-176

27. Q. Wang, J. S. Dordick, R. J. Linhardt, Chem. Mater. 2002, 14, 3232-3244

28. M. Violante de Paz, F. Zamora, B. Begines, C. Ferris, J. A. Galbis, Biomacromolecules, 2010, 11, 269-276

29. M. G. García-Martín, R. R. Pérez, E. B. Hernández, J. A. Galbis, Carbohydr. Res., 2001, 333, 95-103

30. F. Zamora, K. Hakkou, A. Alla, M. Rivas, I. Roffe, M. Mancera, S. MunozGuerra, J. A. Galbis, J. Polym. Sci., Part A: Polym. Chem. 2005, 43, 4570-4577

31. C. Lavilla, A. Alla, A. Martínez de Ilarduya, E. Benito, M. G. García-Martín, J. A. Galbis, S. Munoz-Guerra, Biomacromolecules, 2011, 12, 2642-2652

32. C. Lavilla, A. Alla, A. Martínez de Ilarduya, E. Benito, M. G. García-Martín, J. A. Galbis, S. Múnoz-Guerra1, J. Polym. Sci., Part A: Polym. Chem. 2012, 50, 15911604

33. A. A. Kolender, S. M. Arce, O. Varela, Carbohydr. Res., 2011, 346, 1398-1405

34. D. E. Kiely, L. Chen, T.-H. Lin, J. Polym. Sci. Part A: Polym. Chem., 2000, 38, 594-603

35. M. Mancera, I. Roffé, M. Rivas, J. A. Galbis, Carbohydr. Res., 2003, 338, 11151119

36. C. L. R. Zaliz, R. Erra-Balsells, H. Nonami, Y. Sato, O. Varela, ARKIVOC 2005, xii, 76-87

37. P. Stoss, R. Hemmer, Adv. Carbohydr. Chem. Biochem., 1991, 49, 93-173

38. J. D. Zech, J. W. Le Maistre, US Patent 3272845, 1966

39. A. East, M. Jaffe, Y. Zhang, L. H. Catalani,

(a) US Patent 2008/0021209A1, 2008.

(b) US Patent 2008/0009599A1, 2008

(c) US Patent 7619056 B2, 2009 
40. X. Feng, A. J. East, W. B. Hammond, Y Zhang, M. Jaffe, Polym. Adv. Technol. 2011, 22, 139-150

41. M. Chrysanthos, J. Galy, J.-P. Pascault, Polymer 2011, 52, 3611-3620

42. J. Hong, D. Radojčić, M. Ionescu, Z. S. Petrović, E. Eastwood, Polym. Chem. 2014, 5, 5360-5368

43. R. L. Whistler, M. L. Wolfrom, Methods in Carbohydrate Chemistry, 1963, Vol. II., 326, Academic Press. New York

44. N. K. Richtmeyer, Methods in Carbohydrate Chemistry, 1962, Vol. I., 107, Academic Press. New York

45. D. A. Laidler, J. F. Stoddart, Carbohydr. Res., 1977, 55, C1-C4

46. L. Holmberg, B. Lindberg, B. Lindquist, Carbohyd. Res., 1995, 268, 47-56

47. R. Namme, T. Mitsugi, H. Takahashi, M. Shiro, S. Ikegami, Tetrahedron, 2006, 62, 9183-9192

48. K. Ohta, M. Miura, K. Sakaguchi, F. Sugawara, N. Sato, H. Sahara, N. Takahashi, Y. Mori, T. Yamazuki, K. Masaki, H. Murata, US Patent 2009/0209475 A1, 2009

49. C. Y. Huang, L. A. Cabell, E. V. Anslyn, J. Am. Chem. Soc., 1994, 116, 27782792

50. R. E. Wing, W. M. Doane, C. E. Rist, Carbohyd. Res., 1970, 14, 267-271

51. D. Induragalla, A. J. Bennet, J. Am. Chem. Soc., 2001, 123, 10889-10898

52. P. Calinaud, J. Gelas, In S. Hanessian ed. Preparative Carbohydrate Chemistry, CRC Press, New York, 1997

53. A. L. Bullock, V. O. Cirino, S. P. Rowland, Can. J. Chem., 1966, 45, 255-60

54. B. A. Rozenberg, In K. Dušek ed. Epoxy Resins and Composites II. Adv. Polym. Sci, 1986 Vol. 75, Chapter 4

55. S. Swier, B. Van Mele, J. Polym. Sci. Part B: Polym. Phys., 2003, 41, 594-608 